\title{
Research on the Packaging and Design of Agricultural Products Based on the Mobile Internet
}

\author{
Wei Chen ${ }^{1}$, Peipei $\mathrm{Mu}^{2}$ \\ ${ }^{1}$ Hubei institude of fine arts, Wuhan 430000 , China \\ ${ }^{2}$ Taiyuan university of science and technology, information engineering college, Taiyuan 030000 , \\ China \\ aawei@163.com
}

Keywords: Mobile Interne, agricultural products, packaging and design.

\begin{abstract}
With the development of the mobile Internet, agricultural products sales on the network marketing has become a very important marketing tool. The research of packaging and design of the agricultural products sales on the mobile Internet is an important link in promoting sales and building brands. Through the development of network marketing sales, the packaging situation of agricultural products, the network sales of agricultural products is made a deep research for its packaging and design. It can provide a theoretical support for the packaging and design of agricultural products sales on the mobile Internet and improve the existing system of the packaging and design theory of agricultural products.
\end{abstract}

\section{Introduction}

Along with our country agricultural products sales increased year by year and the rise of the new sales model on the mobile Internet, the network marketing sales of agricultural products has become an important marketing channel. Packaging is a representative of the enterprise image, and it is close to the consumer. Packaging has a huge role on the agricultural products sales and brand promotion. Therefore, the research on network sales characteristics, properties of agricultural products, packaging and design of agricultural products is an important part of promoting agricultural products sales and setting up the agricultural products brand. Through the research of this subject in this paper, on the one hand, it can provide theory support for the mobile Internet sales of agricultural products packaging, make the theoretical system of the existing agricultural products packaging and design to be perfect. On the other hand, we hope to arouse more attention to the network marketing of agricultural products packaging and design, stylist people they are, in particular. We must grasp the dynamic demand of the age and society and combine with the concrete practice, on the background of continuously updated change, standing in a comprehensive and dynamic angle of view to look at design, to combine design performance and the actual needs [1-3].

\section{The Packaging Analysis of Agricultural Products Sales on the Mobile Internet}

Network show. Compared with offline store sales, network marketing rely on strong advantages of web page exhibition, which can not only show the information such as agricultural special products of nutritional value and its origin advantage, but also can be multiple perspectives to show farmers special products physical and packaging. These can increase the sense of consumers on product quality and their trust. Some agricultural products can further reveal a series of links such as its production, processing, transportation and so on. Even it can through dynamic video to make a all-round display for products. Offline stores cannot get rid of the limit of the store space, which is more depend on the display function of packaging to transfer product information. The agricultural special products based on online sales platform get rid of the dependence on packaging told the role of information, which is more to make agricultural products production, processing and other aspects of the comprehensive display. 
Packaging Form. In general, the agricultural products packaging of the network sales mainly includes two forms, one aims at the protection, display and sales. Sales packaging of agricultural products usually choose packaging materials such as plastics, paper and glass. The main display surface of packaging usually adopt hand-drawn illustration, physical form of photography, directly open the window to display their products. Another kind of packaging form is requiring protection, warehousing and logistics transportation as the main goal which is an expressage transportation packing. Storage and transport packing is to ensure that sales packaging from the process of production operators to consumers has the effect of strengthening products protection, it is the link for the buyer and the seller to smoothly realize the online trading, and it is an indispensable form of packaging for shopping online [3-4].

The Function of Packaging. Firstly, packaging has the protection function. Protection function is the main function of packaging. It is to protect goods to avoid a variety of external physical, chemical and mechanical damage and impact in the process of circulation. Packaging can protect products instantly transmit to customers, making consumers to obtain the very good shopping experience, but also it can help buyers and sellers to build a loyal relationship to promote the development of the goods packaging online shopping. Secondly, the packing has the business function. Under the complicated market economy, problems of homogenization of packaging and product are very serious. Packing in business as a symbol of visual communication has become the medium material in the communication between consumer and goods. The business function of packaging mainly refers to the commodity information delivery, beautifying the commodity, and promoting sales, which is based on the basis of scientific and artistic of packaging. Finally, packaging has psychological function. Psychological function of packaging refers that when it applies to person visual sense to some extent, it will result in a corresponding psychological effect [1]. Brand image and visual language of commodity can produce mind-set to consumers, which will directly influence the sale of goods. Juice package is shown in figure 1, which is designed by a Japanese product designers. The yellow color of the packaging is the same as the banana itself. Kiwi fruit juice boxes use the flocking technology to fix fiber on to the paper. Then kiwi fruit packaging will have the effect of surface texture, which is like really kiwi fruit on the vision. The packaging is so fresh and real reduction to give consumers very strong psychological hint that it just like the feeling of the fresh fruit [5-8].

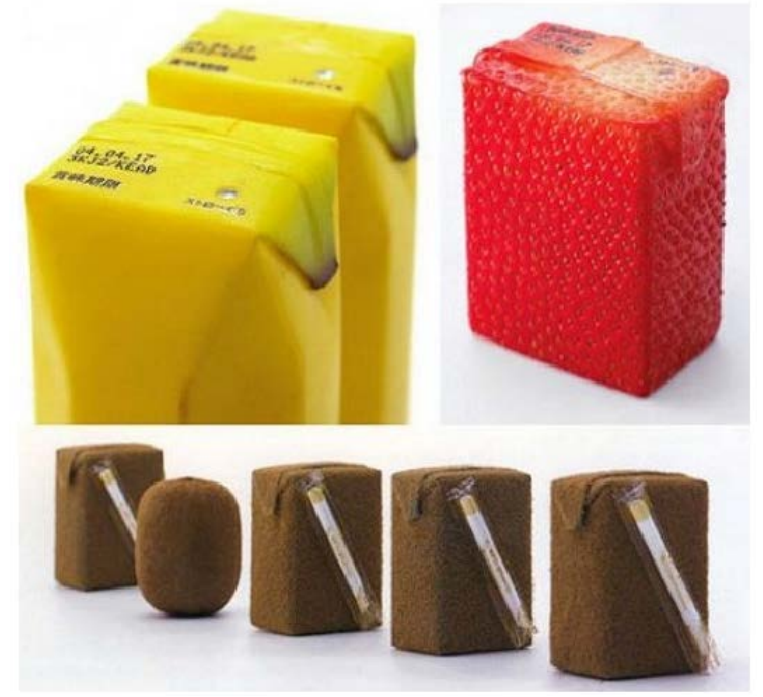

Fig.1 Design of juice boxes

Portfolio Strategy and Packaging Planning. Product portfolio is to point to a compound way of all product number and project of an enterprise. It includes the product's width, length, depth and correlation. Product portfolio strategy is the enterprise according to the market demand, competition situation and their own ability to make decisions for the width, length, depth and correlation of product portfolio. Packaging planning mainly refers to a kind of planning and design by the packaging designer or enterprise. According to the same type, the unity of the different varieties of product of an enterprise or a brand, it usually uses the packing form of both unification and changing. 
For example, Hangzhou Linan Dong Sheng, green food co., LTD. is a company specializing in the pecan, its products are two main types that are a hand peel pecans and pecans. The same kinds of pecans are divided into two flavors butter and salt and pepper. Aim at the different kinds of nuts and walnuts, pecans respectively with different tastes have adopted different packaging strategies for planning. Product packaging is based on the characteristics of each own personality to highlight the commonness of unified style. Using strong visual team to make consumers last knowledge of a certain enterprise or brand product, so as to establish the whole image of the product and deepen the consumer impression of products and enterprises. Then it can achieve the fundamental purpose of promoting sales.

\section{Packaging Design of Agricultural Products on the Mobile Internet}

Through the early market research, after understand the market and potential demand, we should effectively design positioning, namely the consumer positioning, brand positioning and product positioning. When we know the target consumption group characteristics, set the brand essence and are clear about products targeted positioning, we will expand the design work of product packaging. As the most closely relationship with consumers in brand construction, packaging is the most direct part, and it is an important channel to establish brand image. Agricultural products packaging design mainly includes three parts that they are the material and craft, modelling and structure and the content of the visual design.

Packaging Materials. Among the packaging materials in the sales on the mobile Internet, the most widely used materials is paper material and plastic materials, then it is the metal materials, and glass material is seldom used. In addition, in the packaging, especially the storage and transportation packaging will often use all sorts of auxiliary materials to play a role of fixing commodity, reducing the pressure on commodities and protecting the goods. Currently widely used buffer material in the sales online are respectively foam board, bubble bag and the air column. In the figure 2, the foam plate is foam cotton, which is also called EPE pearl cotton. It is a new type of environmentally friendly packaging materials. Its weight is light, and it has a good softness and buffer. In addtion, its thermal conductivity is very low, and its thermal insulation is optimal, and it has a good corrosion resistance. In the figure 3 , bubble film not only has good shock resistance, impact resistance, thermal resistance, but also has a non-toxic, tasteless, moistureproof, corrosion resistance as well as good transparency. It can completely replace the foam plastic protective equipment such as particle fillers to protect your items intact for clients. In the figure 3, it is the air column, which can be $100 \%$ comprehensive protection, it has a close-fitting design whose each independent air chamber can protect your baby. In case, there is one to three permanently damaged, it will not affect the overall package. Inflatable mouth can put inlet air [9-10].

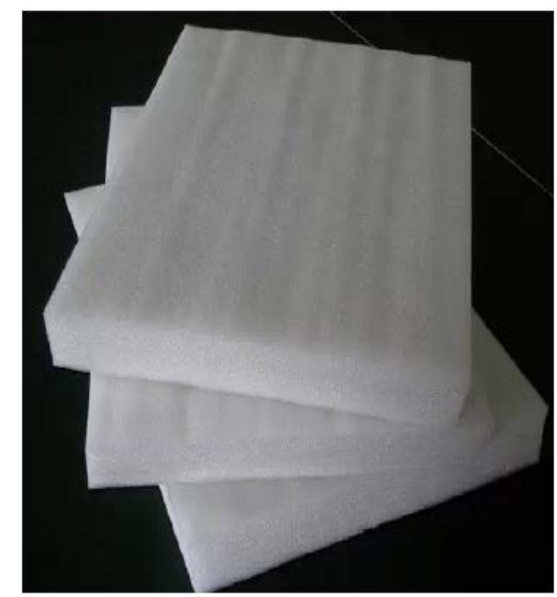

Fig.2 Foam

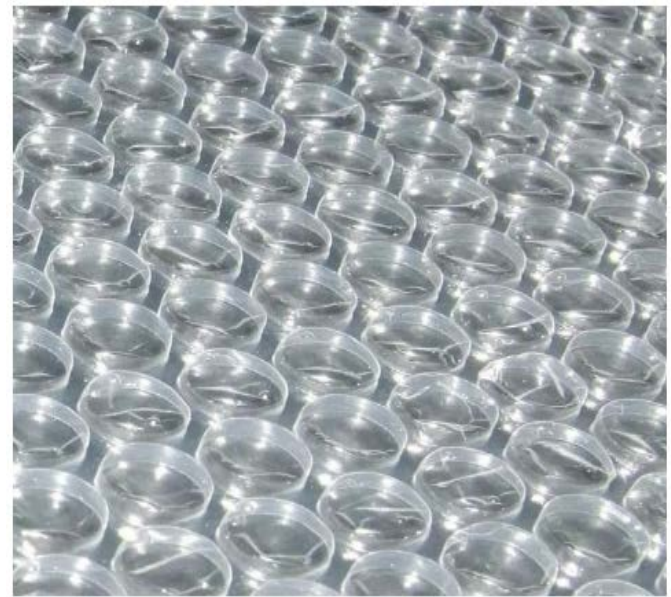

Fig.3 Bubble pack 


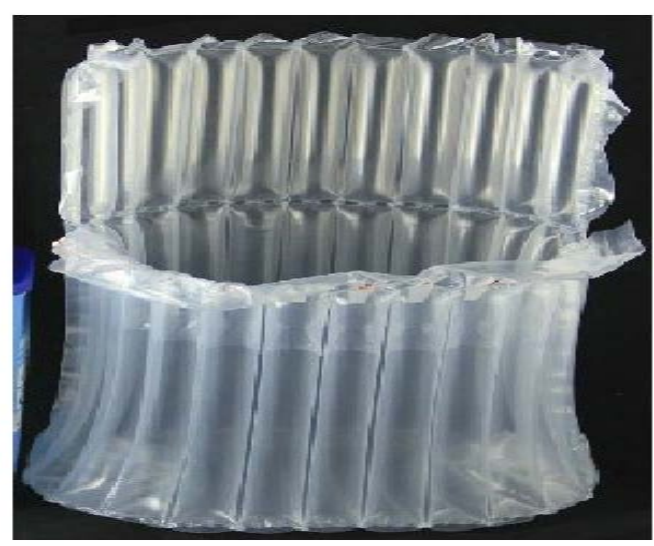

Fig.4 Inflatable columns

Technological Design. Bagging technology is related to the type of paper used as well as the bag making process. Its main link is filling. And the filling method is related to the material type and liquidity. Sealing method of big bag most uses sewing machine for sealing. Small bag technology usually used prefabricated bag technology, the process is picking up bags on bag rack, opening the mouth, filling materials, and the sealing [2]. Carton process includes manual packing craft, semi-automatic packing craft and fully automatic packing craft. Manual packing process is the simplest method, which does not need equipment investment and maintenance cost, but its speed is very slow and the efficiency is very low, and it is easy to cause pollution for contents. For the enterprises whose scale of operation is large, they are more using the semi-automatic box packing process and automatic packing process. In addition, there are metal packaging process and glass packaging process. For example, food cans packaging technology belongs to the metal packaging technology, it includes empty cans, canning, exhaust and sealing, sterilization and cooling, labeling and packing. The glass container is a traditional packing container of food, medicine, chemical industry, it is particularly good adaptability for liquid product packaging $[4,11]$.

Modelling Design. Packaging containers and packaging structure design is based on the requirement of the material of the specific product and the aesthetic function to adopt a certain material structure and the technology to create the three-dimensional shape of packaging, which is the so-called packaging design. Packaging design is different from the general plane expansion of packaging design, it is a kind of three-dimensional modelling activities. Packaging design should consider many factors such as space, shape, material, touch, commodity characteristics and aesthetic and so on. Packaging design can not only effectively accommodate and protect the goods, but also promote the value of goods and establish the brand image. For example, the paper packaging design, plastic packaging design, glass packaging design, metal packing design, etc. [ 12].

Visual Design. Visual communication design of packaging is mainly through the use of graphics, color, text and other visual elements to design. When making a purchase offline, taking super market as examples, once consumers enter into the super market, they'll see a wide variety of goods on the shelf, then the package plays the role of attracting consumers' attention, conveying commodity characteristics, to show enterprise and brand information. So offline sales packing design should highlight the physical information of the product and product brand first. Online sales product packaging is different with the offline. With the help of the web interface and its powerful information to display characteristics, merchants can fully display the product parameters, product content, production, enterprise culture and consumer feedback with text, images and video form. For example, in the visual communication, writing is the core part of the design, any other element of visual communication is for its services. The text of packaging design can be the name of commodity and product name. Consumers can understand information related to the product by reading text, such as commodity name, origin, usage, shelf-life, etc. 


\section{Summary}

As the different environment of sales and display, there has certain differences for the agricultural products packaging and design on the mobile Internet. Its packaging function will more focus on protecting products and showing the brand and reflecting the quality sense and so on. On the one hand, the packaging and design of the mobile Internet marketing agricultural products have to make a packaging plan, including that from the market research to make a consumer positioning, brand and products positioning, and taking the strategies of the combination of products and packaging.

\section{Acknowledgements}

Innovation and Research of Agricultural and products packaging design. 2014 HuBei province Department of Education Humanities and social science research projects of No: 14Q076.

\section{References}

[1] Wang Anxia. Product packaging design (Southeast University Press, China 2009), p.27.

[2] Feng Yingjian. The network marketing basics and practice(Beijing: Tsinghua University Press, China 2004), p.15.

[3] Chen Lei. Go Into the world of packaging design(Beijing: China Light Industry Press, China 2002), p.7.

[4] Wang Jianqing. Packaging materials(Beijing: China Light Industry Press, China 2009), p.1.

[5] Pan Songnian. Packaging technology(Beijing: Printing Industry Press, China 1998), p.9.

[6] Liu Chunlei. Packaging creative design(Beijing: Chemical Industry Press, China 2012), p.2.

[7] Chen Lei. Packaging design(Beijing: China Youth Press, China 2006), p.10.

[8] BAKOS J Y. Astrategic analysis of electronic marketplaces, Vol. 15 (1991) No.9, p. 295-310.

[9] Zhang Wenbin. The research on the packaging problems of China's agricultural products, Vol. 5 (2006) No.3, p. 25-27. (In Chinese)

[10] Luang. Agricultural products packaging optimization strategy, Vol. 12 (2007) No.6, p. 91-95. (In Chinese)

[11] Yang Wenjian. The design of agricultural products brand image construction, Vol. 28 (2011) No.5, p. 789-7936. (In Chinese).

[12] Information on http://www.cnnic.net.cn/hlwfzyj/hlwxzbg/hlwtjbg/201403/t20140305_46240.html 